\title{
Infantile rickets with severe proximal renal tubular acidosis, responsive to vitamin $\mathrm{D}$
}

\author{
M. HUGUENIN, R. SCHACHT, and R. DAVID \\ From Bellevue Hospital Center, New York University School of Medicine, New York
}

\begin{abstract}
Huguenin, M., Schacht, R., and David, R. (1974). Archives of Disease in Childhood, 49, 955. Infantile rickets with severe proximal renal tubular acidosis, responsive to vitamin D. A variant of the Fanconi syndrome is reported in an infant with rickets, hypophosphataemia, severe 'proximal' renal tubular acidosis, and generalized hyperaminoaciduria. Noteworthy was the absence of glycosuria and cystinosis. Large doses of dihydrotachysterol (DHT) and of alkali controlled all of these abnormalities. Renal function tests including glomerular filtration rate, renal blood flow, ammonia secretion, titratable acidity, and bicarbonate handling were normal when the child was receiving DHT. At age $4 \frac{1}{2}$ years total relapse followed the cessation of therapy, and at this time serum parathyroid hormone levels were not raised. Now DHT alone (without alkali supplement) reversed all of the biochemical abnormalities including the acidosis. This child thus has an apparently vitamin D-dependent 'proximal' tubular acidosis, which is not due to secondary hyperparathyroidism.
\end{abstract}

Since Fanconi's original report in 1936, the syndrome which bears his name has come to include a variety of disorders which produce the same spectrum of multiple renal tubular dysfunctions. Broadly defined, this syndrome comprises as its cardinal features the following: hypophosphataemia with rickets or osteomalacia, aminoaciduria, acidosis, and glycosuria. Though many toxic or hereditary factors have been implicated (Dent, 1970), the usual cause is cystinosis which carries a poor prognosis due to progressive renal insufficiency (Fanconi, 1936; Worthen and Good, 1958). A rare form without cystinosis exists in which the outlook may be variable, though in most cases the response to vitamin $\mathrm{D}$ therapy has not been satisfactory (Illig and Prader, 1961).

We here report observations made over a 4-year period in an infant suffering from severe hypophosphataemic rickets, 'proximal' renal tubular acidosis, and generalized aminoaciduria, eventually responding to large doses of dihydrotachysterol (DHT) without alkali supplementation. Renal function studies showed a correlation between bicarbonate excretion and DHT therapy. Serum parathyroid hormone levels were measured after DHT had been temporarily discontinued.

Received 28 May 1974.

\section{Case report}

First admission. A 16-month-old black male was referred to Bellevue Hospital because of rickets resistant to usual antirachitic doses of vitamin $\mathrm{D}$, severe growth retardation, and weight loss. He had been in apparent good health during the first 9 months of life, but later seemed to have pain in his limbs. There was no family history of rickets. Despite treatment with 4000 units vitamin $\mathrm{D}_{2}$ daily for 1 month, then 800 units for 3 months, the child continued to deteriorate and sustained numerous fractures.

On admission his weight was $6.55 \mathrm{~kg}$ (weight age 4.5 months) and length $67 \cdot 3 \mathrm{~cm}$ (height age 6 months). He appeared chronically ill, malnourished, and hypotonic, with rapid respirations. Extreme tenderness of his limbs and signs of severe rickets were the most striking features. No polyuria or excessive thirst were observed. No cystine crystals were seen on repeated slit lamp examinations of the cornea. The main laboratory findings (Table) were (1) hypophosphataemia with a normal serum calcium, (2) hyperchloraemic acidosis, and (3) generalized hyperaminoaciduria. There was no reducing substance in the urine. Serum sodium, potassium, BUN, creatinine, and caeruloplasmin levels were normal. Though the majority of the urinary $p \mathrm{Hs}$ were 7 or higher, several acid urines $(p \mathrm{H} 5)$ were noted, suggesting a 'proximal' renal tubular defect. Urine concentrating ability was intact. Daily urinary calcium excretion varied between 3 and $17 \mathrm{mg}(0.5$ to $2.3 \mathrm{mg} / \mathrm{kg})$ which is normal (Rodriguez-Soriano, 1971). $X$-rays of 
TABLE

Laboratory findings according to age and therapy

\begin{tabular}{|c|c|c|c|c|c|c|c|c|}
\hline & & & & Serum & & & Daily the & \\
\hline Age (yr) & $\begin{array}{l}\text { Amino- } \\
\text { aciduria }\end{array}$ & $\begin{array}{c}\mathrm{Ca} \\
(\mathrm{mg} / 100 \mathrm{ml})\end{array}$ & $\underset{(\mathrm{mg} / 100 \mathrm{ml})}{P}$ & $\begin{array}{l}\text { Alkaline } \\
\text { phosphatase } \\
\text { (Bodansky } \\
\text { units) }\end{array}$ & $\begin{array}{c}\mathrm{HCO}_{3} \\
\text { (mEq/1.) }\end{array}$ & $\underset{(\mathrm{mEq} / \mathrm{l} .)}{\mathrm{Cl}}$ & Vitamin D & $\begin{array}{l}\text { Alkali } \\
\text { (mEq) }\end{array}$ \\
\hline $\begin{array}{rl}1-1 & 4 / 12 \\
1 & 6 / 12 \\
1 & 9 / 12 \\
3 & 5 / 12 \\
3 & 10 / 12 \\
& \\
4 & 3 / 12 \\
4 & 4 / 12 \\
4 & 5 / 12 \\
4 & 6 / 12 \\
4 & 8 / 12 \\
4 & 9 / 12\end{array}$ & $\begin{array}{l}\text { Marked } \\
\text { Slight } \\
\text { Marked } \\
\text { None } \\
\text { Marked }\end{array}$ & $\begin{array}{l}8 \cdot 6-9 \cdot 6 \\
8 \cdot 9 \\
9 \cdot 7 \\
9 \cdot 4 \\
9 \cdot 0 \\
9 \cdot 5 \\
8 \cdot 4 \\
9 \cdot 7 \\
9 \cdot 3 \\
9 \cdot 2 \\
9 \cdot 6 \\
9 \cdot 8 \\
8 \cdot 8\end{array}$ & $\begin{array}{l}2 \cdot 0-2 \cdot 8 \\
3 \cdot 3 \\
3 \cdot 5 \\
4 \cdot 8 \\
2 \cdot 2 \\
2 \cdot 5 \\
4 \cdot 8 \\
4 \cdot 8 \\
3 \cdot 7 \\
4 \cdot 2 \\
2 \cdot 7 \\
2 \cdot 8 \\
2 \cdot 6\end{array}$ & $\begin{array}{l}54-60 \\
18 \\
24 \\
10 \\
29 \\
25 \\
3 \cdot 3 \\
10 \cdot 8 \\
11 \cdot 6 \\
12 \cdot 0 \\
11 \cdot 5 \\
12 \cdot 2 \\
8 \cdot 4\end{array}$ & $\begin{array}{l}13 \cdot 9-18 \\
14 \\
17 \cdot 4 \\
19 \cdot 6 \\
17 \\
18 \\
23 \\
22 \\
20 \\
20 \\
17 \\
16 \\
20 \cdot 3\end{array}$ & $\begin{array}{c}107-112 \\
111 \\
112 \\
104 \\
111 \\
114 \\
102 \\
109 \\
105 \\
107 \\
114 \\
111 \\
108\end{array}$ & $\begin{array}{c}\mathrm{D}_{2} 800 \mathrm{units} \\
\mathrm{D}_{2} 75000 \mathrm{units} \\
\mathrm{DHT} 0.8 \mathrm{mg} \\
\text { DHT } 0.7 \mathrm{mg} \\
0 \\
0 \\
\text { DHT } 0.5 \mathrm{mg} \\
\text { DHT } 0.5 \mathrm{mg} \\
\text { DHT } 0.5 \mathrm{mg} \\
\text { DHT } 0.5 \mathrm{mg} \\
0 \\
0 \\
\text { DHT } 0.6 \mathrm{mg}\end{array}$ & $\begin{array}{r}25 \\
100 \\
100 \\
30 \\
0 \\
0 \\
0 \\
0 \\
0 \\
0 \\
0 \\
0 \\
0\end{array}$ \\
\hline
\end{tabular}

the bones showed advanced rickets with marked thinning of the cortex and trabeculae and multiple pathological fractures (Fig. 1).

The initial course was characterized by a refractoriness to increasing dosage of vitamin D. During the first 6 weeks the child received daily 75,000 units vitamin $D_{2}$ and alkali supplements (Shohl's solution) providing 100 $\mathrm{mEq}$ of base. Vitamin $\mathrm{D}_{2}$ was then substituted with DHT $0.8 \mathrm{mg}$ daily. 3 months later there was radiological evidence of healing rickets, but the acidosis persisted (Table, aged 1 year 9 months).

Complete healing of the rickets was observed by the age of $2 \frac{1}{2}$ years. At 3 years 5 months serum chemistry (Table) and urinary $\mathrm{Ca}$ excretion $(2.4 \mathrm{mg} / \mathrm{kg}$ per day) were normal, and the creatinine clearance was 123 $\mathrm{ml} / \mathrm{min}$ per $1.73 \mathrm{~m}^{2}$. DHT and alkali therapy were discontinued. 5 months later there was recurrence of rickets, hyperaminoaciduria, and hyperchloraemic acidosis (Table, age $310 / 12$ years). Treatment with 0.5 $\mathrm{mg} \mathrm{DHT} /$ day was resumed without any alkali supplement.

Second admission. (Aged 4 years 3 months). The response after 4 months of DHT without alkali was excellent, and all serum values were normal again (Table, aged 4 years 3 months to 4 years 6 months). $X$-rays showed complete healing of rickets (Fig. 2). Linear growth continued at a slow rate, his height being just below the 3rd centile. On this admission renal tubular reabsorption of bicarbonate, titratable acidity, and NH4 secretion were investigated (see Methods and results).

Third admission. (Aged 4 years 8 months). DHT had been discontinued 8 weeks earlier. Again there was recurrence of hypophosphataemia and metabolic acidosis (Table), and urinary excretion of bicarbonate was excessive (20-37 mmol/1.). Serum levels of parathyroid hormone ${ }^{\star}$ measured by radioimmunoassay were not raised $(<0.45 \mathrm{ng} / \mathrm{ml})$. There was no $x$-ray evidence of rickets.

\section{Methods and results}

The following studies were carried out when the child was receiving only DHT, alkali having been discontinued 10 months earlier. His serum electrolytes were normal (Table, aged 4 years 3 months).

Renal response to ammonium chloride infusion. The renal response to an infusion of 3 $\mathrm{mEq} / \mathrm{kg} \mathrm{NH} \mathrm{NH}_{4} \mathrm{Cn} 0.3 \mathrm{~N}$ saline administered over a 2-hour period was normal. Blood $p \mathrm{H}$ and $\mathrm{PCO}_{2}$ decreased from preinfusion values of $7 \cdot 49$ and 30 $\mathrm{mmHg}$, respectively, to $7 \cdot 34$ and $24 \mathrm{mmHg}$ at the end of a 2-hour infusion and were $7 \cdot 37$ and 26 $\mathrm{mmHg} 1$ hour after infusion. Corresponding urine $p H$ s were $6 \cdot 2,5 \cdot 8$, and $4 \cdot 5$. Titratable acid absent in the control urine rose to $72.8 \mu \mathrm{Eq} / \mathrm{min}$ per $1 \cdot 73 \mathrm{~m}^{2}$.

Bicarbonate reabsorption. This was studied by infusion of sodium bicarbonate, inulin, and para-aminohippurate (PAH). After a control period during which the clearances of inulin and PAH were determined (Schreiner, 1950; Smith et al., 1945), increasing amounts of bicarbonate were infused until the urine became alkaline (from $p \mathrm{H} 4.9$ to $7 \cdot 8$ ) and the serum bicarbonate raised. During the control period glomerular filtration rate was 128

^Courtesy of Dr. J. T. Potts, Jr., Massachusetts Gerieral Hospital, Boston. (Normal levels in adults $0 \cdot 2-0 \cdot 7 \mathrm{ng} / \mathrm{ml}$.) 
$\mathrm{ml} / \mathrm{min}$ per $1.73 \mathrm{~m}^{2}$ and renal plasma flow 524 $\mathrm{ml} / \mathrm{min}$ per $1.73 \mathrm{~m}^{2}$; these did not change during bicarbonate infusion. Serum bicarbonate increased gradually from $22 \mathrm{mEq} / 1$. to $27 \mathrm{mEq} / 1$. at the end of a 90-minute infusion of bicarbonate. Urinary bicarbonate excretion was 0 during the control period, $51 \mu \mathrm{Eq} / \mathrm{min}$ per $1.73 \mathrm{~m}^{2}$ when serum bicarbonate was $23 \mathrm{mEq} / \mathrm{l}$., and $193 \mu \mathrm{Eq}$ at the end of the infusion.

Thus, on DHT therapy the child had normal renal haemodynamics and handled bicarbonate in a manner similar to that of normal subjects (Edelmann et al., 1967). Though no comparable studies were available before therapy, it should be noted that when DHT was discontinued (Table, aged 4 years 8 months) the child became acidotic, and his urinary bicarbonate was excessive (20-37 mmol/1.).

\section{Discussion}

The clinical presentation of our patient fits the broad definition of the Fanconi syndrome with rickets, resistant to therapy with vitamin $\mathrm{D}$ in the usual $\mu \mathrm{g}$ range. While not showing glycosuria on casual analyses, the patient had $2+$ glycosuria when he received an intravenous infusion of $5 \%$ glucose with penicillin at a slow rate. No specific cause was found. Prader's pseudo-vitamin D deficiency rickets was deemed unlikely in the absence of hypocalcaemia or tetany, and because of the severity of the renal acidosis.

Of note is the complete reversal of biochemical and radiographical abnormalities after therapy with large doses of DHT, an analogue of vitamin D. Such a favourable response to therapy is unusual in the classical forms of Fanconi's syndrome without 


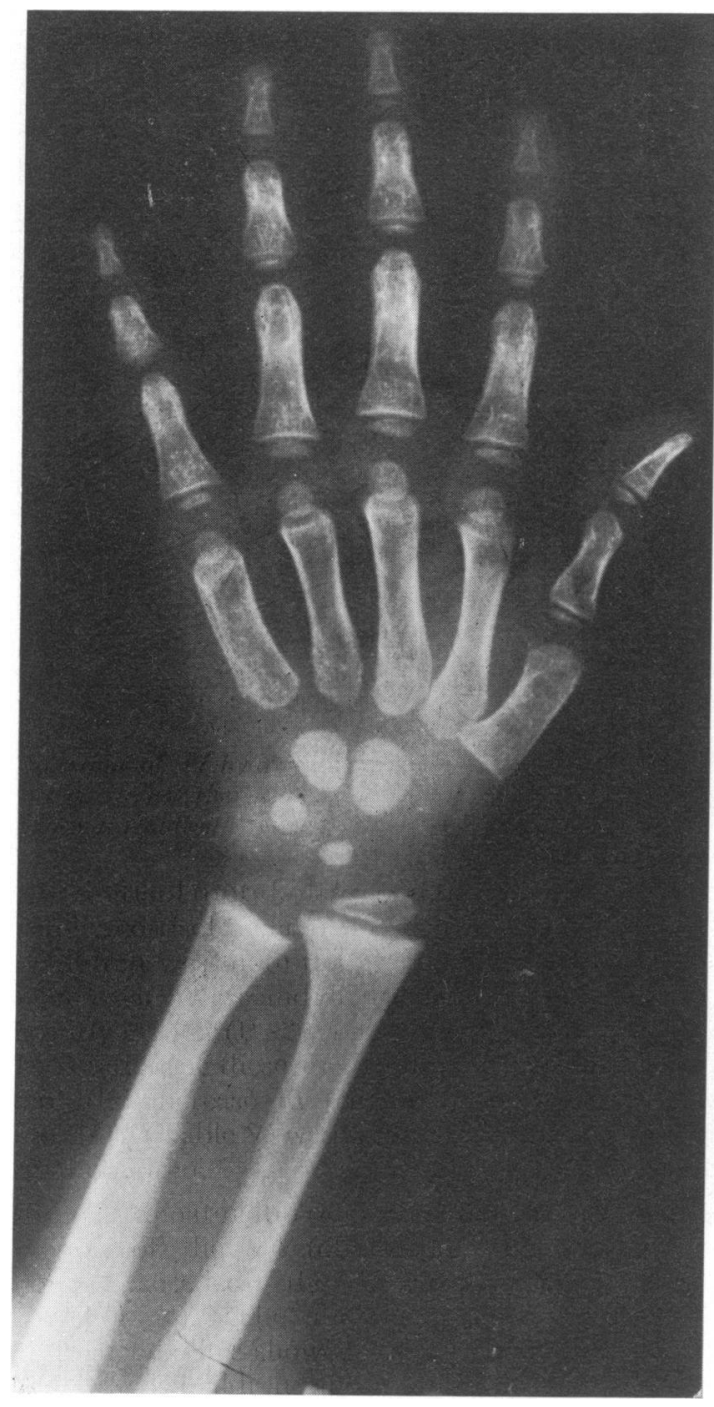

FIG. 2.-Age $4 \frac{1}{4}$ years; healing of rickets.

cystinosis (Illig and Prader, 1961; Haquani and Ram, 1962; McCune, Mason, and Clarke, 1943). A review of 26 cases of this syndrome without cystinosis indicated only limited clinical improvement in most, and a fatal outcome in 3 of the patients was reported (McCune et al., 1943). However, the response to therapy and prognosis can be variable (Saville et al., 1955).

The demonstration of a normal urinary acidification mechanism (urinary $p H$ 5), and a normal concentrating ability before the initiation of alkali therapy, strongly suggested a proximal renal tubular acidosis (Rodriguez-Soriano, 1971; RodriguezSoriano et al., 1967). This was corroborated by the subsequent finding of bicarbonaturia as acidosis ensued after DHT therapy was stopped. A normal renal threshold for bicarbonate was attained only when therapy was reinstituted. It therefore appears that the defect in proximal tubular function causing acidosis, aminoaciduria, and rickets was dependent upon and responsive to DHT, the mechanism being unknown.

While Muldowney et al. (1971) suggested that the proximal tubular acidosis and aminoaciduria in most forms of rickets are primarily due to the action of parathyroid hormone and not to vitamin D deficiency or resistance, our data do not permit us to apply such a theory in our patient. His initial $x$-rays suggested that the gross rickets may have been complicated by secondary hyperparathyroidism. However, the subsequent course of the disease, with a normal level of circulating parathyroid hormone when the child was in relapse, suggested that the acidosis, hypophosphataemia, and aminoaciduria were not due to secondary hyperparathyroidism. Therapy with DHT alone again restored his biochemical findings to normal.

Bergstrom reported a normalization of bicarbonate and healing of rickets with calciferol in cases of multiple tubular dysfunction (Bergstrom, 1968). A common tubular transport system for phosphate and bicarbonate was proposed. In 2 children with Fanconi's syndrome, Salassa et al. noted normalization of serum phosphate, bicarbonate, and chloride after 30 days of intensive vitamin therapy (Salassa et al., 1954). There is evidence that the action of vitamin $D$ on the renal tubule is to increase the reabsorption of phosphate, the primary buffer in the urine (Puschett, Moranz, and Kurnick, 1972; Harrison and Harrison, 1941). It is reasonable to suppose that an additional action of vitamin $\mathrm{D}$ affects the proximal renal tubule in either a direct or indirect manner (Puschett et al., 1972). This action might facilitate the reabsorption not only of phosphate but also of glucose, bicarbonate, and amino acids.

The synthetic compound DHT was utilized as the therapeutic agent as its action is not dependent upon kidney metabolism (Harrison and Harrison, 1972) and its use might therefore be preferable to the calciferols in the presence of renal disease. The stereo-chemical configuration of DHT closely resembles that of 1,25 -dihydroxy $D_{3}$, the active metabolite of vitamin $D$ which is formed only in the kidney (Fraser and Kodicek, 1970). Several recent studies have shown the physiological importance of 
1,25-dihydroxy $D_{3}$ with respect to the mobilization of skeletal calcium and its absorption by the intestine (Myrtle and Norman, 1971; Tanaka and DeLuca, 1971), and its therapeutic efficacy in advanced renal disease and in vitamin $\mathrm{D}$ dependent rickets (Brickman, Coburn, and Norman, 1972; Fraser et al., 1973) has been shown. Future work with this and other metabolites of vitamin D in the Fanconi syndrome may clarify their role in the transport of bicarbonate and phosphate across the proximal tubule.

We thank the nursing staff of the Clinical Research Center for expert help, and Miss V. Catenaccio for secretarial assistance. This study was supported by USPHS Grant No. RR-05399-10.

\section{REFERENCES}

Bergstrom, W. H. (1968). The response of multiple renal tubular dysfunction to calciferol. Pediatric Research, 2, 408.

Brickman, A. S., Coburn, J. W., and Norman, A. W. (1972). Action of 1,25-dihydroxycholecalciferol, a potent, kidney-produced metabolite of vitamin $\mathrm{D}_{3}$, in uremic man. New England fournal of Medicine, $287,891$.

Dent, C. E. (1970). Rickets (and osteomalacia), nutritional and metabolic (1919-69). Proceedings of the Royal Society of Medicine, 63, 401.

Edelmann, C. M., Jr., Rodriguez-Soriano, J., Boichis, H., Gruskin, A. B., and Acosta, M. I. (1967). Renal bicarbonate reabsorption and hydrogen ion excretion in normal infants. Fournal of Clinical Investigation, 46, 1309.

Fanconi, G. (1936). Der nephrotisch-glykosurische Zwergwuchs mit hypophosphatämischer Rachitis. Deutsche Medizinische Wochenschrift, 62, 1169.

Fraser, D. R., and Kodicek, E. (1970). Unique biosynthesis by kidney of a biologically active vitamin D metabolite. Nature, 228, 764.

Fraser, D., Kooh, S. W., Kind, H. P., Holick, M. F., Tanaka, Y., and DeLuca, H. F. (1973). Pathogenesis of hereditary vitamin-Ddependent rickets. New England Fournal of Medicine, 289, 817.

Haquani, A. H., and Ram, M. M. (1962). Renal tubular insufficiency. A report of 10 cases and the results of calcium infusion on the renal clearance of inorganic phosphates. Fournal of Pediatrics, 61, 242.

Harrison, H. E., and Harrison, H. C. (1941). The renal excretion of inorganic phosphate in relation to the action of vitamin $\mathrm{D}$ and parathyroid hormone. Fournal of Clinical Investigation, 20, 47.
Harrison, H. E., and Harrison, H. C. (1972). Dihydrotachysterol : a calcium active steroid not dependent upon kidney metabolism. Fournal of Clinical Investigation, 51, 1919.

Illig, R., and Prader, A. (1961). Primäre Tubulopathien. 11. Ein Fall von idiopathischem Gluko-Amino-Phosphat-Diabetes (de Toni-Debré-Fanconi syndrome). Helvetica Paediatrica Acta, $16,622$.

McCune, D. J., Mason, H. H., and Clarke, H. T. (1943). Intractable hypophosphatemic rickets with renal glycosuria and acidosis (the Fanconi syndrome). American Fournal of Diseases of Children, 65, 81.

Muldowney, F. P., Carroll, D. V., Donohoe, J. F., and Freaney, R. (1971). Correction of renal bicarbonate wastage by parathyroidectomy: implications in acid-base homeostasis. Quarterly fournal of Medicine, 40, 487.

Myrtle, J. F., and Norman, A. W. (1971). Vitamin D: a cholecalciferol metabolite highly active in promoting intestinal calcium transport. Science, 171, 79.

Puschett, J. B., Moranz, J., and Kurnick, W. S. (1972). Evidence for a direct action of cholecalciferol and 25-hydroxycholecalciferol on the renal transport of phosphate, sodium, and calcium. Fournal of Clinical Investigation, 51, 373.

Rodriguez-Soriano, J. (1971). The renal regulation of acid-base balance and the disturbances noted in renal tubular acidosis. Pediatric Clinics of North America, 18, 529.

Rodriguez-Soriano, J., Boichis, H., Stark, H., and Edelmann, C. M., Jr. (1967). Proximal renal tubular acidosis: a defect in bicarbonate reabsorption with normal urinary acidification. Pediatric Research, 1, 81.

Salassa, R. M., Power, M. H., Ulrich, J. A., and Hayles, A. B. (1954). Observations on the metabolic effects of vitamin $D$ in Fanconi's syndrome. Proceedings of the Mayo Clinic, 29, 214.

Saville, P. D., Nassim, R., Stevenson, F. H., Mulligan, L., and Carey, M. (1955). The Fanconi syndrome: metabolic studies on treatment. Fournal of Bone and foint Surgery, 37-B, 529.

Schreiner, G. E. (1950). Determination of inulin by means of resorcinol. Proceedings of the Society for Experimental Biology and Medicine, 74, 117.

Smith, H. W., Finkelstein, N., Aliminosa, L., Crawford, B., and Graber, M. (1945). Renal clearances of substituted hippuric acid derivatives and other aromatic acids in dog and man. fournal of Clinical Investigation, 24, 388.

Tanaka, Y., and DeLuca, H. F. (1971). Bone mineral mobilization activity of 1,25-dihydroxycholecalciferol, a metabolite of vitamin D. Archives of Biochemistry and Biophysics, 146, 574.

Worthen, H. G., and Good, R. A. (1958). The de Toni-Fanconi syndrome with cystinosis. American Fournal of Diseases of Children, 95, 653.

Correspondence to Dr. R. David, Department of Pediatrics, New York University Medical Center, 550 First Avenue, New York, New York 10016, U.S.A. 